\title{
Primary HIV Infection with Acute Transverse Myelitis
}

\author{
Yohei Hamada ${ }^{1}$, Koji Watanabe ${ }^{1}$, Takahiro Aoki ${ }^{1}$, Noritoshi Arai $^{2}$, Miwako Honda ${ }^{1}$, \\ Yoshimi Kikuchi ${ }^{1}$ and Shinichi Oka ${ }^{1}$
}

\begin{abstract}
Primary HIV infection (PHI) is associated with various neurological disorders. However, acute transverse myelitis (ATM) complicating PHI has not been reported after the introduction of the combination antiretroviral therapy (cART). We encountered one patient with known PHI with clinical presentation of ATM. Treatment with cART and corticosteroids successfully improved symptoms, and no recurrence was noted after discontinuation of cART. In conclusion, concurrent use of cART and corticosteroids was effective against PHI accompanied by ATM and could be withdrawn after improvement of ATM.
\end{abstract}

Key words: acute transverse myelitis, primary HIV infection, cART

(Intern Med 50: 1615-1617, 2011)

(DOI: 10.2169/internalmedicine.50.5186)

\section{Introduction}

Primary HIV infection (PHI) is associated with various neurological disorders $(1,2)$. However, PHI complicated with acute transverse myelitis (ATM) had only been reported before the availability of combination antiretroviral therapy (cART) (3). We report a case of ATM, successfully treated with cART and corticosteroids.

\section{Case Report}

A 30-year-old homosexual man visited a local hospital with 5-day history of systemic skin eruption, high fever and sore throat. Although these symptoms disappeared spontaneously within one week, PHI was suspected because of the positive result of 4th generation HIV diagnostic test. He was referred to the clinic of our hospital for further management. PHI was confirmed by the negative result of Western blot analysis and high HIV-RNA level (6.38 log copies $/ \mathrm{mL})$ with a CD4 count of $601 / \mu \mathrm{L}$. No treatment for HIV infection was provided because the patient was asymptomatic at that stage. However, he subsequently developed urinary retention and abnormal sensation in the lower limbs, and he returned to the clinic 2 days later. On admission, neurological examination showed normal function of the cranial nerves and no nuchal stiffness. Motor system assessment showed no paresis. The deep tendon reflexes were exaggerated in the lower extremities but normal in the upper extremities. Pathological reflexes such as Babinski reflex and Chaddock sign were not noted. Sensory system examination showed bilateral hypoesthesia and hypalgesia below the level of Th7, and deep sensation was preserved in all extremities. Urinary retention was observed and anal muscle tone was reduced. The cranial and entire spinal magnetic resonance imaging (MRI), with and without gadolinium enhancement, showed no abnormal findings. Examination of the cerebrospinal fluid (CSF) showed mild pleocytosis (cell count: $8.0 / \mu \mathrm{L}$, mononuclear cells $6.0 / \mu \mathrm{L})$, a normal protein level $(29 \mathrm{mg} / \mathrm{dL})$, and normal $\operatorname{IgG}$ index (0.62). The CSF level of myelin basic protein (MBP) was elevated to $1857.3 \mathrm{pg} / \mathrm{mL}$ (normal range: $<102 \mathrm{pg} / \mathrm{mL}$ ). Herpes simplex virus, varicella zoster virus, cytomegalovirus and Epstein-Barr virus DNA were negative in the CSF on polymerase chain reaction assay.

ATM was diagnosed by the typical neurological findings with spinal cord inflammation, which was proceeded by PHI. Upon the diagnosis, cART of lopinavir/ritonavir plus abacavir/lamivudine and methylprednisolone pulse treatment (1000 mg for 3 days) were initiated (Fig. 1). The treatment resulted in immediate and rapid improvement of clinical symptoms, and all symptoms disappeared by treatment day 6. The MBP level (less than $31.2 \mathrm{pg} / \mathrm{mL}$ ) and cell count

${ }^{1}$ AIDS Clinical Center, National Center for Global Health and Medicine, Japan and ${ }^{2}$ Department of Neurology, National Center for Global Health and Medicine, Japan

Received for publication January 20, 2011; Accepted for publication March 29, 2011

Correspondence to Dr. Yohei Hamada, yhamada@acc.ncgm.go.jp 


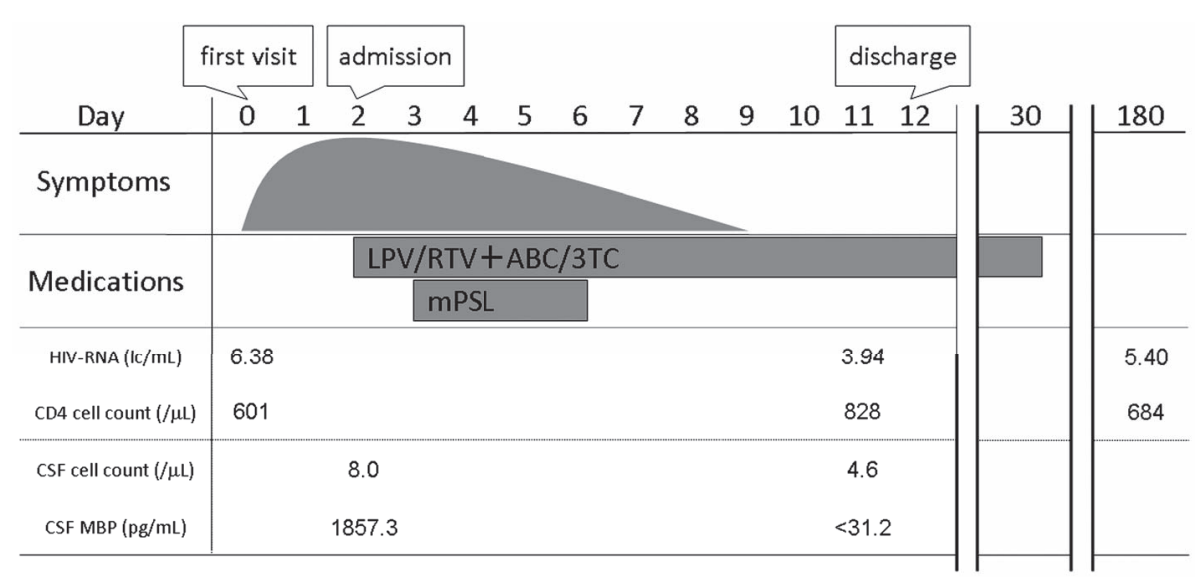

Figure 1. Clinical course. LPV: Lopinavir, RTV: Ritonavir, ABC: Abacabir, 3TC: Lamivudine, mPSL: methylprednisolone, CSF: cerebrospinal fluid, MBP: myelin basic protein

(4.6/ $/ \mathrm{L})$ in the CSF decreased to the normal ranges at treatment day 9. Methylprednisolone was given for 3 days and cART was continued for one month, which resulted in no relapse of ATM-related symptoms in the subsequent 6 months (Fig. 1), and also no resistant mutation was seen in Protease and Reverse Transcriptase lesions of HIV (data not shown).

\section{Discussion}

ATM is a segmental spinal cord injury caused by acute inflammation characterized by acute or subacute motor, sensory, and autonomic (genitourinary and digestive systems) spinal cord dysfunction $(4,5)$. Although preceding infection is noted in $20-50 \%$ of cases (4, 6-9) ATM associated with PHI was only reported before the era of cART (3). There is currently no standard treatment for ATM. Although corticosteroids are the first-line treatment due to the probable mechanisms such as molecular mimicry and the development of autoantibodies, approximately 30 to $50 \%$ of patients develop severe sequelae $(4,10,11)$.

In the present patient, ATM was diagnosed by the rapid development of symptoms, neurological findings, including clearly-defined bilateral sensory deficits below Th7 level, autonomic dysfunction, and MBP elevation, suggestive of spinal cord inflammation $(4,5)$. Furthermore, PHI was diagnosed just before the onset of ATM, based on the absence of bands in Western blot analysis and a high titer of HIV-RNA level. It was concluded that PHI was the trigger of ATM.

Although direct cytopathic effects of the virus and immune-mediated toxicity are suggested, pathogenesis of PHI is not fully understood (12-14). There are case reports of rapid improvement of PHI-related symptoms after cART initiation, even though the HIV-RNA level was not completely suppressed at the time of clinical resolution $(15,16)$. Regarding these phenomena, it is assumed that inhibition of viral replication by cART induces the resolution of symptoms. In the present case, complete recovery was achieved by the combination of steroids and cART $(4,11,12)$.
In conclusion, concurrent use of cART and corticosteroids was effective against PHI accompanied by ATM. The immediate improvement in ATM allowed the subsequent discontinuation of treatment.

\section{The authors state that they have no Conflict of Interest (COI).}

\section{References}

1. Mielke J. Neurological complications of human immunodeficiency virus infection in Zimbabwe-2005. J Neurovirol 11 (Suppl 3): 2325, 2005.

2. Bell SK, Little SJ, Rosenberg ES. Clinical management of acute HIV infection: best practice remains unknown. J Infect Dis 202 (Suppl 3): S278-S288, 2010.

3. Denning DW, Anderson J, Rudge P, Smith H. Acute myelopathy associated with primary infection with human immunodeficiency virus. Br Medl J (Clinical Res Ed) 294: 143-144, 1987.

4. Frohman EM, Wingerchuk DM. Clinical practice. Transverse myelitis. N Engl J Med 363: 564-572, 2010.

5. Group TMCW. Proposed diagnostic criteria and nosology of acute transverse myelitis. Neurology 59: 499-505, 2002.

6. Fux CA, Pfister S, Nohl F, Zimmerli S. Cytomegalovirusassociated acute transverse myelitis in immunocompetent adults. Clin Microbiol Infect 9: 1187-1190, 2003.

7. Karacostas D, Christodoulou C, Drevelengas A, et al. Cytomegalovirus-associated transverse myelitis in a nonimmunocompromised patient. Spinal Cord 40: 145-149, 2002.

8. de Seze J, Lanctin C, Lebrun C, et al. Idiopathic acute transverse myelitis: application of the recent diagnostic criteria. Neurology 65: 1950-1953, 2005.

9. Kaplin AI, Krishnan C, Deshpande DM, Pardo CA, Kerr DA. Diagnosis and management of acute myelopathies. Neurologist 11: 2-18, 2005.

10. Greenberg BM, Thomas KP, Krishnan C, Kaplin AI, Calabresi PA, Kerr DA. Idiopathic transverse myelitis: corticosteroids, plasma exchange, or cyclophosphamide. Neurology 68: 1614-1617, 2007.

11. Kerr DA, Ayetey H. Immunopathogenesis of acute transverse myelitis. Current Opinion in Neurology 15: 339-347, 2002.

12. Kassutto S, Rosenberg ES. Primary HIV type 1 infection. Clin Infect Dis 38: 1447-1453, 2004.

13. Hicks CB, Gay C, Ferrari G. Acute HIV infection: the impact of anti-retroviral treatment on cellular immune responses. Clin Exp Immunol 149: 211-216, 2007. 
Intern Med 50: 1615-1617, 2011 DOI: 10.2169/internalmedicine.50.5186

14. Kahn JO, Walker BD. Acute human immunodeficiency virus type 1 infection. N Engl J Med 339: 33-39, 1998.

15. Wong TY, So MK. Primary human immunodeficiency virus infection: heightened awareness needed. Hong Kong Med J 7: 205-208, 2001.

16. Furusyo N, Ariyama I, Chong Y, et al. A patient with primary hu- man immunodeficiency virus infection for whom highly active antiretroviral therapy was successful. J Infect Chemother 8: 361-364, 2002.

(C) 2011 The Japanese Society of Internal Medicine http://www.naika.or.jp/imindex.html 